\title{
As dimensões do planejamento educacional: o que os educadores precisam saber, de Pablo Silva Machado Bispo dos Santos
}

São Paulo: Cengage Learning, 2016. 152 p.

Gabriela Barbosa

Mestranda em Educação pelo programa de Pós-Graduação em Educação da Universidade Nove de Julho (PPGE-UNINOVE), Linha de Pesquisa Políticas Educacionais (LIPED). São Paulo - SP - Brasil gabrielabie@gmail.com

Doutor em Educação pela PUC-Rio, Professor Adjunto IV da Universidade Federal Fluminense e Membro do Conselho Universitário, o autor epigrafado ministra aulas na Graduação e no Programa de Pós-Graduação em Educação (PPGEDUC) dessa Universidade. É líder do Núcleo de Pesquisa em Instâncias de Socialização, Políticas Públicas e Movimentos Sociais (Polis-UFF) e coordenador do Curso de Especialização em Gestão Educacional - Escola de Gestores SEB/ MEC/UFF e do Programa de Monitoria do Departamento de Ciências Humanas da UFF - PCH/UFF. Tem ampla experiência na área de Educação, com ênfase em História da Educação e Política Educacional, atuando principalmente nos seguintes temas: Avaliação de Planos, Programas e Ações Políticas, História das instituições educacionais e científicas e Pesquisa Educacional. É autor dos livros: Guia prático da política educacional no Brasil (2012) e Princípios da metaciência social (2013) $)^{1}$.

A obra objeto desta resenha foi escrita para promover teorias e práticas relacionadas ao planejamento educacional e traz, também, propostas de estudo e de investigação, além de uma metodologia de análise do ciclo do planejamento educacional. O objetivo do autor, na presente obra, é proporcionar ao leitor uma visão geral sobre a temática do planejamento educacional, propondo sanar questões por ele encontradas ao estudar a fundo a epistemologia do tema. Levanta questões que indagam se o planejamento educacional é uma ciência e, em sendo, se estudos de obras de autores como Carnoy ${ }^{2}$ podem servir de auxílio no entendimento das variáveis que podem ser interferentes e se é possível prever tais variáveis. 
Escrito em linguagem bem elaborada, de forma clara e organizada, o autor apresenta um guia de noções e conceitos básicos no campo do planejamento educacional para professores, gestores, planejadores e demais profissionais da área interessados no que se refere ao planejamento anual, plano de aula, parâmetros curriculares, organização de conteúdo, projetos político-pedagógicos etc.

O autor divide o livro em três partes, sendo que cada uma delas é composta por quatro capítulos que, em sua ordem, decorrem em uma espécie de manual didático para aqueles interessados no assunto.

A primeira parte, nominada de "Reflexões teóricas e marcos conceituais" transita pelos capítulos que tratam de noções, conceitos básicos, dimensões, interfaces e pesquisas do planejamento educacional.

Nessa primeira parte, o autor traz os fundamentos que se referem a conceitos básicos do planejamento, conceitos estes relacionados ao plano, projeto, escopo e às definições. Esse capítulo abrange não só teorias para aplicação em sala; evidencia, também, como se pode utilizar o planejamento em qualquer momento da vida, permitindo entendê-lo como uma atividade humana. $O$ autor ainda elucida como ações estratégicas, com gerenciamento e administração, conseguem auxiliar a prever alternativas de planos para que um objetivo seja alcançado.

Em defesa de sua concepção, o autor não separa administração do planejamento e da gestão, por entender que essas funções são dimensões que se complementam e interpenetram. Esses elementos combinados são diretrizes essenciais e seguras para um planejamento educacional que visa atender a necessidades e objetivos.

Ainda na primeira parte do livro, são apresentados autores, concepções e experiências que se referem ao planejamento educacional no Brasil. Nessa parte, são citados autores que se consagraram em cada momento da história da educação do país. Referentemente ao período de 1950-1960, o autor cita Anísio Teixeira, apontado como autor da ideia de planejar a educação brasileira a partir da elaboração de uma política de formação de professores e da organização de uma rede de centros de pesquisa educacional aplicada. Já no período que vai de 1960-1970, o autor fala sobre Dumerval Trigueiro Mendes, um autor de concepção de planejamento educacional avançada. O autor finaliza essa primeira parte explicando metodologia da pesquisa e cada uma de suas abordagens: quantitativa, qualitativa, experimental; seus olhares teóricos: objetivista, subjetivista, relacional, enfoques teóricos: fenomenológico, crítico-dialético, positivista, histórico e, por 
fim, as técnicas: questionários, observação, entrevista semiestruturada, grupo focal e análise de documentos.

Chegando à segunda parte do livro, depara-se com as lições da prática. Trata de políticas públicas educacionais e de planejamento educacional, suas noções básicas e como se configuram ações práticas, concretas, direcionadas aos contextos educativos. Nessa parte, é possível entender que o planejamento é responsável pela identificação dos elementos políticos e educacionais que se consagram em um projeto e expressam o pensamento dos grupos formuladores de políticas públicas educacionais que, com ajustes, se exprimem na forma de planos e se concretizam em políticas que serão implantadas. Resumidamente, o ciclo de políticas públicas se inicia com a formulação e se conclui com a construção do plano, passando pelo projeto da política pública educacional. No que tange a planejamento de políticas públicas, o autor enaltece a relação entre políticas públicas e planejamento educacional e que o processo de formulação dessas políticas é multidimensional e dinâmico.

É nessa parte que aproveita para trazer questões financeiras da educação das escolas públicas e privadas. Então são analisadas as relações entre o planejamento educacional e o financiamento das redes escolares, tendo como foco o desenvolvimento de projetos e planos educacionais. Também aí trata o planejamento como princípio da administração pública, a fim de equilibrar os recursos financeiros em atendimento às normas da administração pública.

Logo após mostrar seu ponto de vista com relação às questões financeiras, o autor passa para um capítulo que traz lições de planejamento educacional oferecidas por escolas e redes de ensino que dão certo. Nesse mesmo capítulo 7, é desenvolvido um debate sobre a escola que queremos. Dessa forma, o autor brinda o leitor, com um histórico de experiências educacionais bem-sucedidas, sugerindo a aplicação desses procedimentos em outras realidades. O autor encerra a segunda parte do livro levantando questões sobre rendimento escolar e qualidade social, com definições de qualidade e qualidade educacional, nas etapas do planejamento educacional, concluindo que se deve delinear a relação de quantidade e qualidade em matéria educacional para que seja realizado um trabalho pedagógico de qualidade.

A terceira e última parte do livro configura um esboço de manual para planejadores, com documentos escolares para professores: plano de aula e plano de ensino. Esse manual foi escrito, já que algumas escolas utilizam planos desti- 
nados aos professores, mas seus modelos não se encontram disponíveis, criando dificuldades no momento de sua elaboração por parte dos professores. Discorre também sobre procedimentos relativos à construção do plano de aula e do plano de ensino, indicando como utilizar esses documentos no ciclo do planejamento educacional.

Essa parte também apresenta a construção de planos de aula em etapas, sendo o planejamento trazido como estudo dos conteúdos que serão distribuídos pelo tempo de aula, modelagem do projeto, que é a etapa em que a forma da aula é delineada, e o plano como registro escrito e na sucessão das etapas do projeto. $\mathrm{O}$ autor se refere ao plano de ensino como sendo a estrutura organizacional do planejamento educacional. Segundo ele, "os planos de ensino possuem como matéria as aulas e como forma a descrição detalhada das aulas e das atividades de ensino que serão projetadas no espaço e no tempo" (p. 98). Para o sucesso desse plano, algumas etapas devem ser seguidas: elaboração do plano de ensino, modelagem do plano de ensino e a concretização do plano de ensino.

A docência nas escolas não pode ser realizada sem um planejamento educacional e toda atividade a ela relacionada deve ser vista como uma oportunidade de reflexão teórico-prática da ação do educador.

Nessa parte, encontra-se ainda um exame de documentos escolares para gestores. O autor explica qual a função do regimento escolar e as dimensões do projeto político-pedagógico (PPP), sendo elas: dimensão pedagógica, dimensão infraestrutural e dimensão administrativa. Explicita, também, os elementos do PPP: proposta pedagógica da escola, quadros administrativos e mapa da gestão. Mostra, ainda, as etapas de construção do ciclo do planejamento educacional: planejamento, projeto e consolidação do plano do PPP. E explica como utilizar dados e indicadores de larga escala para planejar políticas educacionais. Para utilizar esses dados e indicadores corretamente, devem-se levar em consideração fatores demográficos, econômicos e educacionais referentes às unidades avaliadas, sem falar que deve se observar também fatores, tais como distorção idade-série, índice de analfabetismo e taxa de evasão escolar, singularidades essas que impactam as realidades educacionais.

Antes de concluir o livro, apresenta um esquema para elaboração de planos educacionais para escolas e redes de ensino, utilizando indicadores demográficos educacionais (IDE) e, por fim, propõe uma síntese geral do que foi visto no decorrer da obra, discutindo se o planejador é um profeta. 
O principal mérito da obra é a sistematização de teorias e práticas relacionadas ao planejamento educacional. Escrita em estilo claro e objetivo, a obra é científica na forma em que aborda os modelos, mas é de fácil leitura e compreensão.

Ao separar o estudo dos modelos do estudo das teorias e epistemologias, o autor acaba por gerar alguma repetição. Não se pode criticar estas pequenas redundâncias, uma vez que, pelo caráter didático do livro e pela própria divisão escolhida pelo autor, a repetição seria inevitável.

Dirigida a estudantes, pesquisadores e profissionais da área da educação, o investimento que se faz na leitura do livro resulta em benefícios e aprendizado para o leitor. A obra auxilia os profissionais quanto à teoria e à prática do planejamento educacional, entendendo o contexto histórico, social e econômico e ainda guiando o profissional nas práticas mais eficazes para o sucesso de um plano político pedagógico com a ideia de um modelo de planejamento que leva ao alcance de um plano pedagógico de sucesso.

\section{Notas}

1 Informações disponíveis em http://lattes.cnpq.br/9398557494803815

2 Martin Carnoy, nascido em 1938, é professor na Universidade Stanford, formado em Engenharia Elétrica pelo Instituto de Tecnologia da Califórnia, Mestre e PhD em Economia pela Universidade de Chicago e consultor do Banco Mundial, do Banco de Desenvolvimento Interamericano, do Banco de Desenvolvimento Asiático, da Unesco, da Unicef e da Organização para a Cooperação e Desenvolvimento Econômico (OCDE). 
